\title{
Relationships among the Microstructure, Mechanical Properties, and Fatigue Behavior in Thin Ti6Al4V
}

\author{
Y. Fan, ${ }^{1,2}$ W. Tian, ${ }^{1}$ Y. Guo, ${ }^{1}$ Z. Sun, ${ }^{1}$ and J. $X u^{1}$ \\ ${ }^{1}$ School of Material Science and Engineering, China University of Mining and Technology, Xuzhou, Jiangsu 221116, China \\ ${ }^{2}$ Faculty of Engineering, University of Nottingham, University Park, Nottingham NG7 2RD, UK \\ Correspondence should be addressed to Y. Fan; fanyu@cumt.edu.cn
}

Received 14 September 2015; Revised 9 December 2015; Accepted 10 January 2016

Academic Editor: Michele Iafisco

Copyright ( $) 2016$ Y. Fan et al. This is an open access article distributed under the Creative Commons Attribution License, which permits unrestricted use, distribution, and reproduction in any medium, provided the original work is properly cited.

\begin{abstract}
The microstructures of Ti6Al4V are complex and strongly affect its mechanical properties and fatigue behavior. This paper investigates the role of microstructure on mechanical and fatigue properties of thin-section Ti6Al4V sheets, with the aim of reviewing the effects of microstructure on fatigue properties where suboptimal microstructures might result following heat treatment of assemblies that may not be suited to further annealing, for example, following laser welding. Samples of Ti6Al4V sheet were subjected to a range of heat treatments, including annealing and water quenching from temperatures ranging from $650^{\circ} \mathrm{C}$ to $1050^{\circ} \mathrm{C}$. Micrographs of these samples were inspected for microstructure, and hardness, $0.2 \%$ proof stress, elongation, and fracture strength were measured and attributed back to microstructure. Fractography was used to support the findings from microstructure and mechanical analyses. The strength ranking from high to low for the microstructures of thin Ti6Al4V sheets observed in this study is as follows: acicular $\alpha^{\prime}$ martensite, Widmanstätten, bimodal, and equiaxed microstructure. The fatigue strength ranking from high to low is as follows: equiaxed, bimodal, Widmanstätten, and acicular $\alpha^{\prime}$ martensite microstructure.
\end{abstract}

\section{Introduction}

Ti6Al4V alloy is widely used in the medical device industry [1-3] for its many desirable properties, including its strength to weight ratio, corrosion resistance, biocompatibility, and processability [4-8]. Titanium components in medical devices are usually manufactured from very thin sections $(<1 \mathrm{~mm})$, and it is common for such products to be hermetically sealed by laser-beam welding [3]. Some welded components made of thin Ti6Al4V sheets are subjected to static and cyclic loading, from which fatigue, fracture, and failure may eventually occur. The mechanical properties (strength and toughness) and fatigue behavior of thin Ti6Al4V sheets are evaluated from the viewpoint of finding optimal properties for use in medical devices. Previous research has indicated that mechanical properties and fatigue behavior are quite sensitive to microstructure $[5,9,10]$. The microstructures are controlled by heat treatment, generally at temperatures in the dual $\alpha-\beta$ phase region $[11,12]$.

The microstructures of titanium alloys are generally described by the size and arrangement of their $\alpha$ and $\beta$ phases.
The two extreme cases of phase arrangements are lamellar microstructure (with a greater $\alpha / \beta$ surface area and more oriented colonies), which is generated upon cooling from the $\beta$ phase field, and equiaxed microstructure (a uniform structure composed of $\alpha$ grains and grain boundaries of $\beta$ [7]), which results from a recrystallization and globularization process [13]. Previous research has indicated that lamellar microstructure exhibits lower strength, lower ductility, and better fatigue propagation resistance compared with equiaxed microstructure [14]. Equiaxed microstructure provides better fatigue initiation resistance but poorer propagation resistance [13] than lamellar microstructure. Another kind of structure, called bimodal microstructure, is considered to be a combination of lamellar and equiaxed microstructures. Bimodal microstructures exhibit a well-balanced fatigue properties profile [13], since they combine the advantages of both lamellar microstructure (i.e., higher fatigue crack propagation resistance) and equiaxed microstructure (i.e., higher fatigue crack initiation resistance). During heat treatment, Widmanstätten microstructure may be found in Ti6Al4V [15]; this is observed when materials are cooled at a critical 
rate from extremely high temperature. For example, Ahmed and Rack [16] showed that, for heat treatment at $1050^{\circ} \mathrm{C}$ for $30 \mathrm{~min}$ and at a low cooling rate $\left(<20^{\circ} \mathrm{C} \mathrm{s}^{-1}\right), \alpha$ colonies change into a basket-weave structure (Widmanstätten). The slow cooling rate results in nucleation and growth of Widmanstätten plates. There is no full definition for the Widmanstätten microstructure of titanium alloy much beyond the appearance of the characteristic basket-weave structure. The Widmanstätten microstructure may be considered to be a special type of lamellar microstructure (with thicker lamellar width and greater orientation with long, coarse $\alpha$ grain boundaries). Rapid quenching (or laser-beam welding) leads to a martensitic transformation of $\beta$, which causes a very fine needle-like microstructure. Unlike ferrous martensite, titanium martensite is neither significantly stronger nor more brittle [17] than its parent phase, and the hardening effect of titanium alloy martensite is only moderate.

The weld zone in laser-beam welding consists of melted and resolidified metal resulting from a process lasting only a short period of time. Hence, the fusion zone (FZ) has properties similar to those resulting from a water-quenching process from a high temperature. The fatigue behavior of $\alpha^{\prime}$ martensite is generally seen as poor, because the dislocations concentrate on the martensite interfaces on the tip of the fatigue crack in the FZ, forming a high-density dislocation network. Microplastic deformation occurs at and near the tip of the crack, forming a large deformation zone. Fine martensite laths obstruct the motion and emission; consequently, the stress concentration induces shear fracture of the laths $[18,19]$. In thin Ti6Al4V laser welding, the martensite laths tend to be even finer owing to the greater cooling rate, which aggravates fatigue crack [18].

Hence, it is necessary to improve the fatigue behavior of laser-welded Ti6Al4V by transforming martensite to another microstructure. The purpose of this paper is to study the effect of microstructure produced by different cooling rates on the mechanical properties of as-received (AR) parent material (PM) $0.7 \mathrm{~mm}$ Ti6Al4V sheets. The fatigue behavior of bimodal, Widmanstätten, and martensite microstructures transformed from the AR materials is also studied.

\section{Experimental Procedures}

The material used in this study was $0.7 \mathrm{~mm}$ sheet Ti6Al4V alloy (grade 5). Following rolling, the sheet was heat-treated at $850^{\circ} \mathrm{C}$ for $8 \mathrm{~h}$, followed by heat treatment at $750^{\circ} \mathrm{C}$ for $30 \mathrm{~min}$, and then furnace-cooled to room temperature; this defines its AR state.

Samples for microstructural analysis were mounted in conductive hot-mounting resin. The samples were ground with 240-mesh silicon carbide papers (to remove any oxide layer), followed by 400-, 800-, and 1200-mesh silicon carbide papers, and finally polished using a porous neoprene polishing disk to a mirror finish. The samples were etched with a mixture of $2 \mathrm{~mL} \mathrm{HF}, 5 \mathrm{~mL} \mathrm{HNO}_{3}$, and $93 \mathrm{~mL} \mathrm{H}_{2} \mathrm{O}$. A Nikon Optiphot $200 \mathrm{D}$ microscope (Nikon Corporation, Tokyo, Japan) was used for the examination of microstructural features of the original and heat-treated samples. A Philips XL30

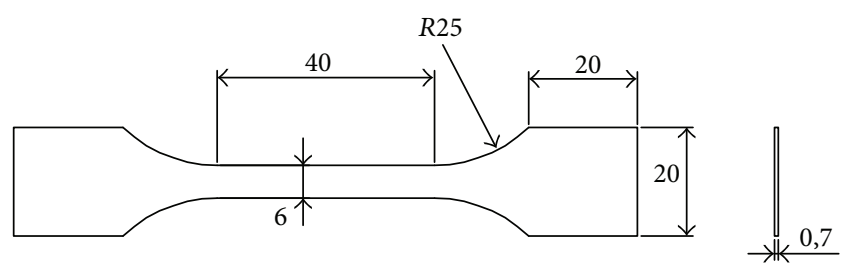

Figure 1: Sample dimensions for the tensile test.

tungsten filament scanning electron microscope (FEI, North America NanoPort, 5350 NE Dawson Creek Drive, Hillsboro, OR 97124, USA) was used to image and characterize the samples.

The tensile test experiments were performed on an Instron 5569 tensile and compression test machine (Instron, Coronation Road, High Wycombe, Bucks HP12 3SY, UK) at room temperature with a load cell capacity of $50 \mathrm{kN}$ and crosshead speed of $1 \mathrm{~mm} \mathrm{~min}^{-1}$. The tensile test samples were designed to comply with European Standard EN10002-1 [20]; their dimensions are shown in Figure 1. Two strain gauges were used for measurement of strain:

(i) A strain gauge was attached to the gauge section of the sample and was used to measure tensile strains $<0.2 \%$.

(ii) At higher strains, the crosshead movement was used to calculate the strains in the gauge section of the sample.

Three samples of each of the AR materials and heattreated materials were tested to failure.

The microhardness of the samples was measured using Vickers hardness with a Leco M-400 tester (Leco ${ }^{\circ}$ Corporation, 3000 Lakeview Avenue, St. Joseph, MI 49085-2396, USA), over a $15 \mathrm{~s}$ indentation time. A $200 \mathrm{gf}$ load was used for all hardness measurements.

Two types of furnaces were used:

(i) A rapid heat furnace (Carbolite RHF 16/3, ELITE Thermal Systems, 6 Stuart Road, Market Harborough, Leicestershire LE16 9PQ, UK) from Carbolite was adopted for the water-quenching process. The samples were heat-treated for $8 \mathrm{~min}$ until the furnace reached the required temperature and then waterquenched.

(ii) A Lenton argon furnace (Lenton Furnaces and Ovens, P.O. Box 2031, Hope, Hope Valley, Derbyshire S33 $6 \mathrm{BW}, \mathrm{UK})$ was used for the annealing process. Argon was used as a shielding gas along with a Cussons rare gas purifier-4 (Cussons Technology, 102 Great Clowes Street, Manchester M7 1RH, UK). The samples were soaked in the furnace at temperatures of $650^{\circ} \mathrm{C}$, $750^{\circ} \mathrm{C}, 850^{\circ} \mathrm{C}, 950^{\circ} \mathrm{C}$, and $1050^{\circ} \mathrm{C}$ for $1 \mathrm{~h}$ and then furnace-cooled to room temperature. Before these tests, the furnace was calibrated and the cooling curve was recorded. The average cooling rate of the argon furnace was $0.075^{\circ} \mathrm{C} \mathrm{s}^{-1}$.

A Denison Mayes 250-kN-capacity servohydraulic machine (Denison Mayes Group, Moor Road, Leeds, West 


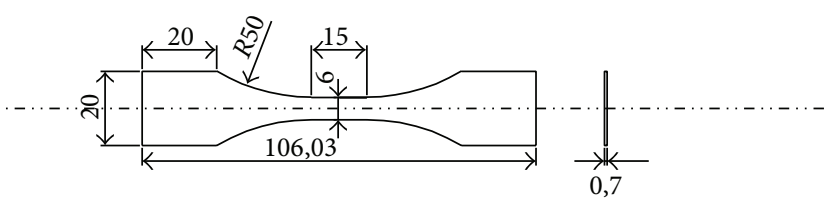

FIGURE 2: Sample dimensions for tensile fatigue test pieces.

Yorkshire LS10 2DE, UK) was used for tensile fatigue testing. Figure 2 shows a schematic diagram of the tensile fatigue test pieces designed to comply with British Standard 3518-1 [21].

The stress ratio used for all samples was 0.1 and the cycling frequency was $7 \mathrm{~Hz}$. Five samples were tested to at least $10^{7}$ life cycles.

\section{Results}

3.1. Microstructures and X-Ray Diffraction of Heat-Treated Ti6Al4V. The microstructure of Ti6Al4V AR material exhibited equiaxed $\alpha$ phase surrounded by a $\beta$ phase boundary with fine grain size $(15-20 \mu \mathrm{m})$. The hardness, Young's modulus, $0.2 \%$ proof stress, and elongation of the AR material were, respectively, $362 \mathrm{HV}, 111 \mathrm{GPa}, 978 \mathrm{MPa}$, and $13.6 \%$. Other samples of Ti6Al4V material were heat-treated at $650^{\circ} \mathrm{C}, 750^{\circ} \mathrm{C}, 850^{\circ} \mathrm{C}, 950^{\circ} \mathrm{C}$, and $1050^{\circ} \mathrm{C}$ for $1 \mathrm{~h}$ followed by annealing. Following heat treatment, samples were inspected for their microstructural development. In the following results, the nomenclature " $\mathrm{A}$ " indicates annealed samples that have been cooled in the furnace and "Q" indicates waterquenched samples. Optical images of samples at different heat-treatment temperatures and cooling rates are shown in Figure 3. There is no significant difference in samples of $650 \mathrm{~A}$ (Figure 3(b)), 750A (Figure 3(d)), 850A (Figure 3(f)), 650Q (Figure 3(c)), and 750Q (Figure 3(e)). All of these images exhibit equiaxed $\alpha$ phase surrounded by a $\beta$ phase boundary. There is a slight difference between 850Q (Figure 3(g)) and others, where the $\beta$ phase boundary appears thicker. In 950A (Figure 3(h)), an equiaxed microstructure with primary $\alpha$ phase and a partial $\beta$ phase boundary still exists, but some transformation from the $\beta$ phase boundary to lamellar $\alpha+\beta$ phase has occurred. At 950Q (Figure 3(i)), an equiaxed microstructure with primary $\alpha$ phase and a partial $\beta$ phase boundary is observed, which is similar to $950 \mathrm{~A}$. The difference is that there is no lamellar $\alpha+\beta$ phase but, instead, a region of metastable $\beta$ phase (dark region) that has been transformed from the $\beta$ phase boundary regions is observed. Figure 3(j) (1050A) shows a typical basket-weave Widmanstätten microstructure with an $\alpha$ grain boundary in the prior $\beta$ grains from annealed $1050^{\circ} \mathrm{C}$ samples. Figure $3(\mathrm{k})$ (1050Q) shows needle-like $\alpha^{\prime}$ martensite microstructure with $\beta$ phase between martensitic laths. The grain size tends to be coarse. The results of quantitative microscopy giving the volume fraction of phases for all different heat treatments are summarized in Table 1.

The SEM backscattered electron images of AR material (equiaxed), 950A (bimodal), 1050A (Widmanstätten), and 1050Q (martensite) are shown in Figure 4.
TABLE 1: Volume fraction results of $\alpha / \beta \beta^{\prime}$ phases.

\begin{tabular}{lccccc}
\hline & $\alpha$ phase & $\beta$ phase & & $\alpha$ phase & $\beta$ phase \\
\hline $650 \mathrm{~A}$ & Rest & 6.132 & $650 \mathrm{Q}$ & Rest & 7.143 \\
$750 \mathrm{~A}$ & Rest & 4.930 & $750 \mathrm{Q}$ & Rest & 8.645 \\
$850 \mathrm{~A}$ & Rest & 8.638 & 850Q & Rest & 15.335 \\
950A & Rest & 21.575 & 950Q & Rest & 22.767 \\
$1050 \mathrm{~A}$ & Rest & 42.638 & 1050Q & $62.738\left(\alpha+\alpha^{\prime}\right)$ & 37.262 \\
\hline
\end{tabular}

X-ray diffraction patterns of PM, 950A, 1050A, and 1050Q are shown in Figure 5, respectively. Reflections of $\alpha$ and $\beta$ phase were detected in diffraction patterns of equiaxed, bimodal, Widmanstätten, and martensite. It should be noted that $\beta$ reflections are rather weak, suggesting a relatively low volume fraction of the $\beta$ phase (Table 1) in PM and 950A.

3.2. Mechanical Properties. Hardness testing was conducted on heat-treated Ti6Al4V samples. Figure 6 shows the results of hardness examination of Ti6Al4V heat-treated at $650^{\circ} \mathrm{C}$, $750^{\circ} \mathrm{C}, 850^{\circ} \mathrm{C}, 950^{\circ} \mathrm{C}$, and $1050^{\circ} \mathrm{C}$ for $1 \mathrm{~h}$ with annealing (A) and water quenching $(\mathrm{Q})$, respectively. There is no significant change of hardness values among 650A, 750A, 850A, 650Q, and 750Q. Following the annealing process, hardness values increased from $850^{\circ} \mathrm{C}$ to $1050^{\circ} \mathrm{C}$; the highest hardness value for an annealed sample occurred at $1050^{\circ} \mathrm{C}(7.41 \%$ higher than for the AR sample). Following water quenching, hardness values increased from between $750^{\circ} \mathrm{C}$ and $850^{\circ} \mathrm{C}$ to $1050^{\circ} \mathrm{C}$; the highest hardness value is $15.58 \%$ higher than that for the AR sample.

The trends (Figure 7 ) of $0.2 \%$ proof stress values of heat-treated Ti6Al4V following both annealing and water quenching are very similar to those of the hardness values. The highest proof stress value occurred at a $1050^{\circ} \mathrm{C}$ waterquenching condition, which is $13.78 \%$ higher than that of the AR sample.

The value of elongation to failure of samples deteriorated following annealing or water quenching following heat treatment in the temperature range $650^{\circ} \mathrm{C}-1050^{\circ} \mathrm{C}$, as seen in Figure 7 . There is no significant change of elongation values among 650A, 750A, 850A, 650Q, and 750Q. In annealing, elongation values decrease between $850^{\circ} \mathrm{C}$ and $1050^{\circ} \mathrm{C}$; the lowest elongation value is $24.38 \%$ less than that of the $\mathrm{AR}$ material. In the water-quenched condition, elongation values dropped off more quickly from a point between $750^{\circ} \mathrm{C}$ and $850^{\circ} \mathrm{C}$ and $1050^{\circ} \mathrm{C}$. The lowest elongation value was $42.73 \%$ smaller than that of the AR sample.

Stress-strain curve of heat-treated Ti6Al4V following both annealing and water quenching from different temperatures are shown in Figure 8.

3.3. Fatigue Behavior. Figure 9 shows the high-cycle fatigue fracture lives of the AR material, martensite microstructure, Widmanstätten microstructure, and bimodal microstructure transformed by 1050Q, 1050A, and 950A, respectively. Fatigue strength (at $10^{7}$ cycles) of the AR material is $180 \mathrm{MPa}$, which was the highest for all microstructures. 1050Q had the highest $0.2 \%$ proof stress, but its fatigue strength was 


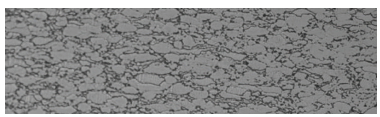

(a) PM
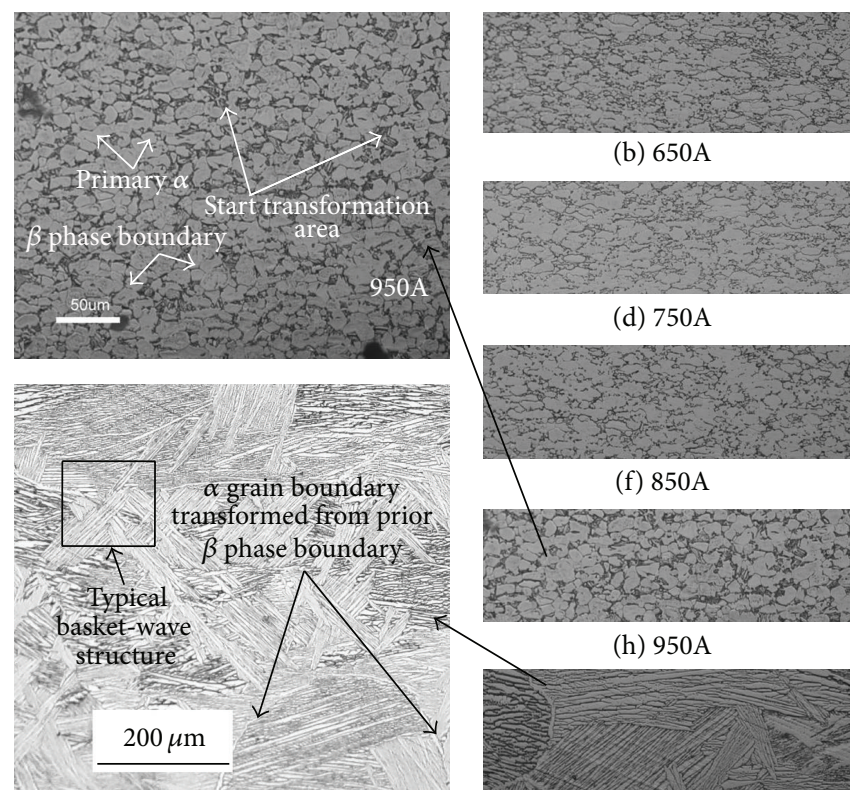

(b) $650 \mathrm{~A}$

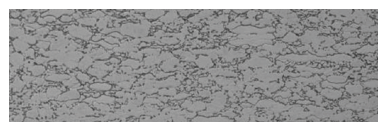

(d) $750 \mathrm{~A}$

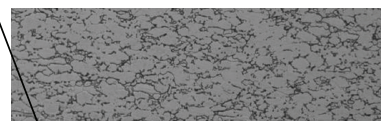

(f) $850 \mathrm{~A}$

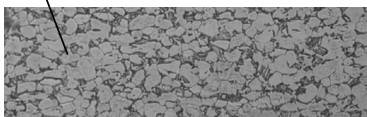

(h) $950 \mathrm{~A}$

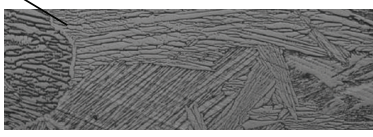

(j) $1050 \mathrm{~A}$

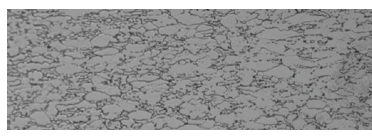

(c) $650 \mathrm{Q}$

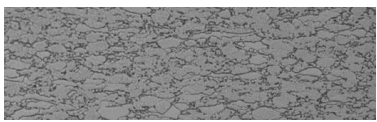

(e) $750 \mathrm{Q}$

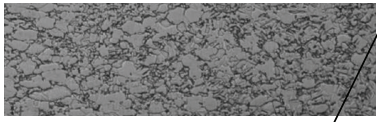

(g) $850 \mathrm{Q}$

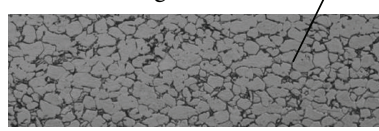

(i) $950 \mathrm{Q}$

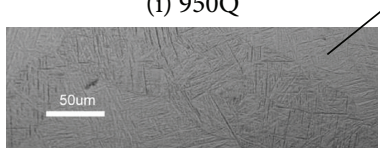

(k) $1050 \mathrm{Q}$
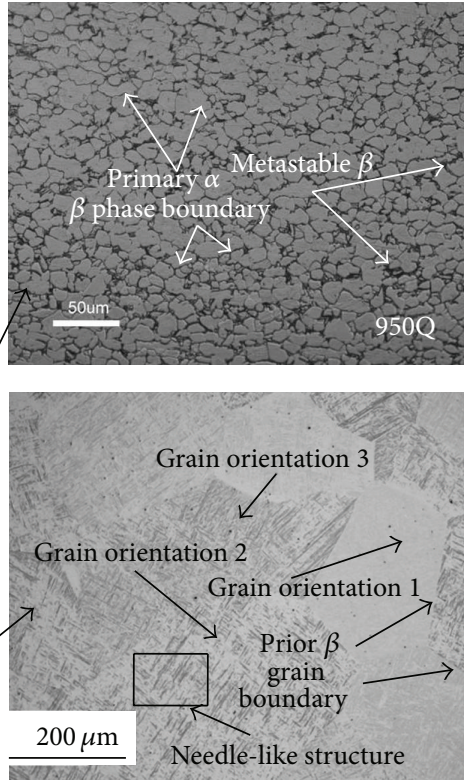

$200 \mu \mathrm{m}$

FIgURE 3: Optical microstructure of AR material and heat-treated Ti6Al4V. The number indicates the heat-treatment temperature. "A" indicates annealing (furnace-cooled) and "Q" indicates quenching.

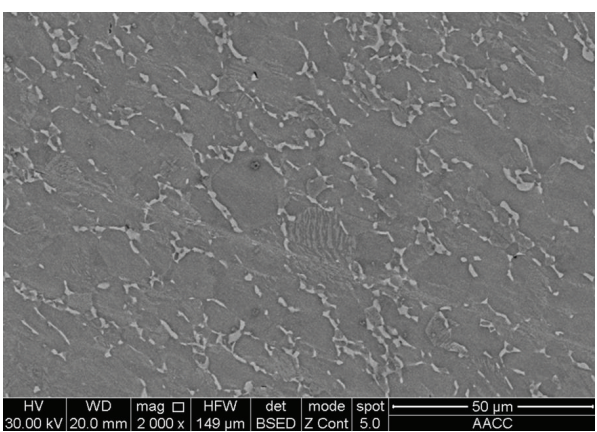

(a) PM

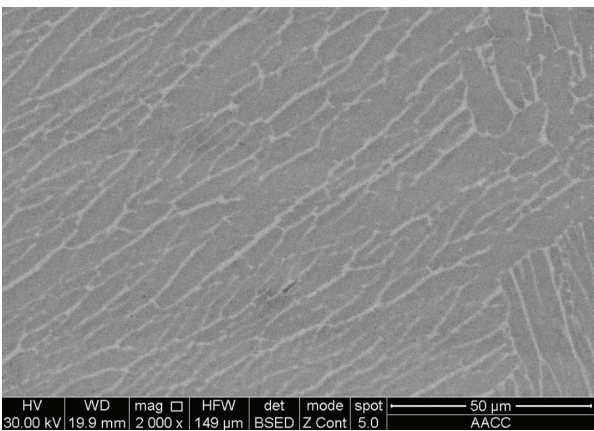

(c) $1050 \mathrm{~A}$

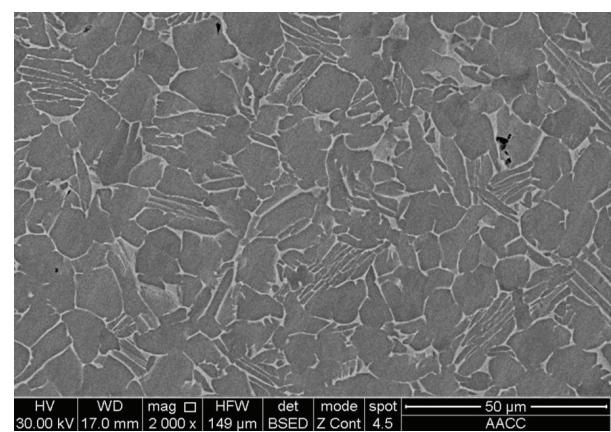

(b) $950 \mathrm{~A}$

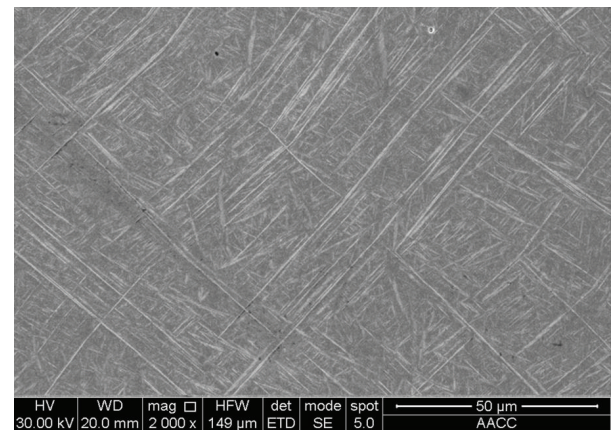

(d) $1050 \mathrm{Q}$

FIGURE 4: SEM backscattered electron images of AR-PM, 950A, 1050A, and 1050Q. 


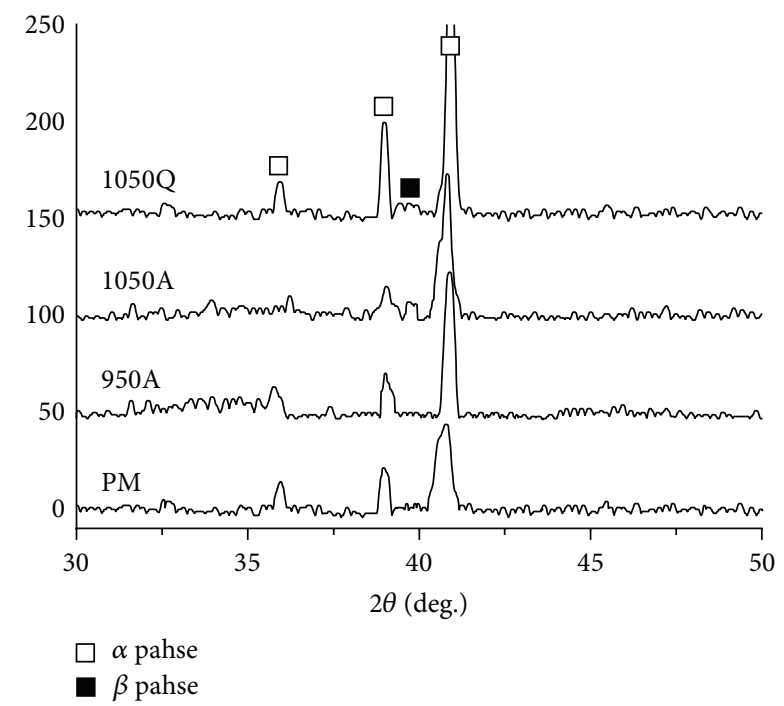

FIGURE 5: X-ray diffraction pattern of PM, 950A, 1050A, and 1050Q.

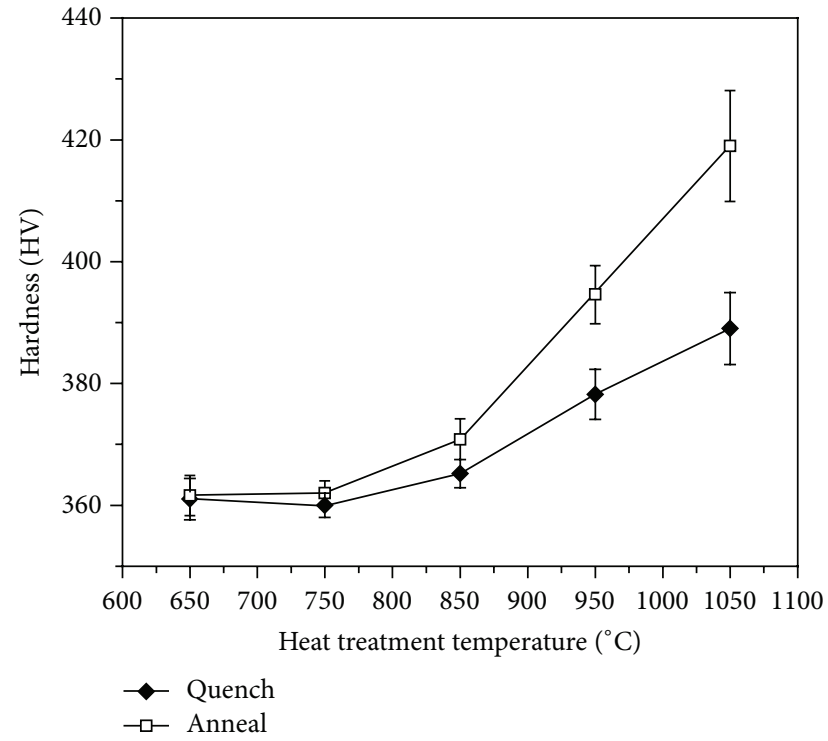

FIGURE 6: Effect of annealing temperatures and cooling schedules on hardness of Ti6Al4V.

lowest (135 MPa). The fatigue strength of 1050A (158 MPa) was slightly higher than that of $950 \mathrm{~A}(153 \mathrm{MPa})$.

3.4. Ti6Al4V Fractographs. Figure 10 shows SEM fractographs of fatigue crack propagation areas of AR material, 1050Q (martensite microstructure), 950A (bimodal microstructure), and 1050A (Widmanstätten microstructure). The fractograph of AR material (Figure 10(a)) is flat and uniform. Fine dimple patterns were observed. However, the fracture surface of the martensite microstructure is rougher, as shown in Figure 10(b). The appearance of mountain-shape patterns indicates typical brittle fatigue fracture. The fracture surface of the bimodal microstructure is flat but not as

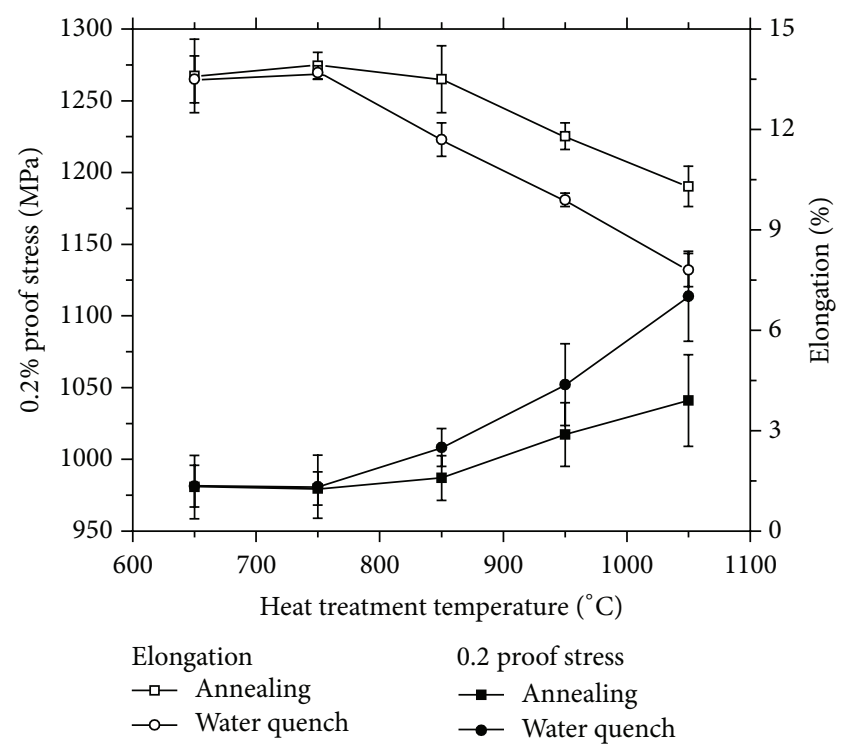

FIGURE 7: Effect of different heat-treatment temperatures on $0.2 \%$ proof stress and elongation of Ti6Al4V.

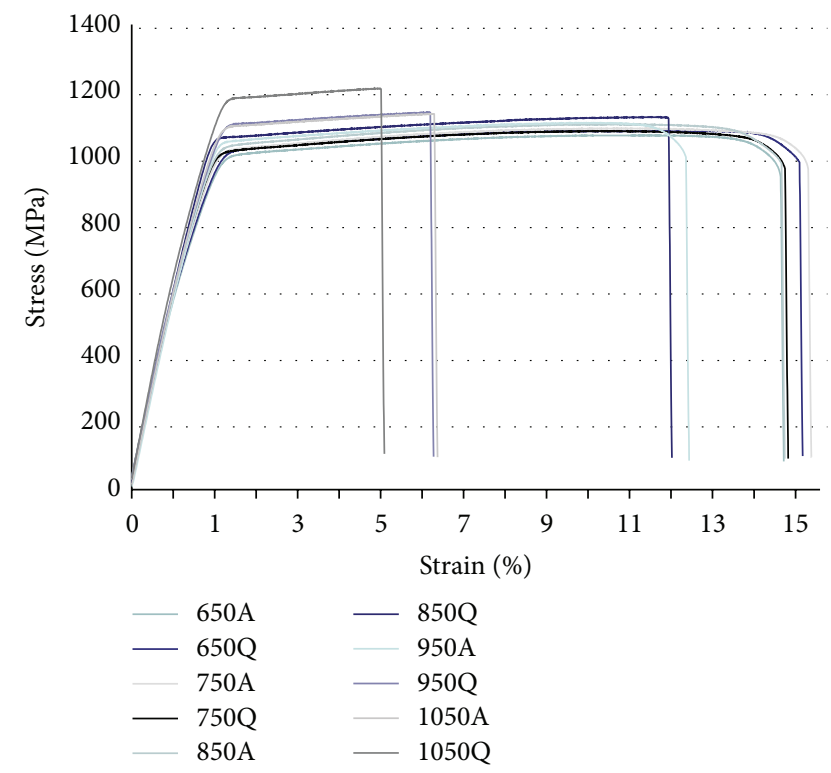

FIGURE 8: Stress-strain curve of heat-treated Ti6Al4V following both annealing and water quenching from different temperatures.

uniform as exhibited in AR material (Figure 10(c)). River patterns are observed in the fractograph of the Widmanstätten microstructure (Figure 10(d)).

\section{Discussion}

The different microstructures are generated by heat treatment of the AR material $[10,22,23]$. Generally, most of the commercially used Ti6Al4V has been heat-treated via a complex sequence of solution heat treatment, deformation, aging, and annealing [5] for stress relief, recrystallization, 


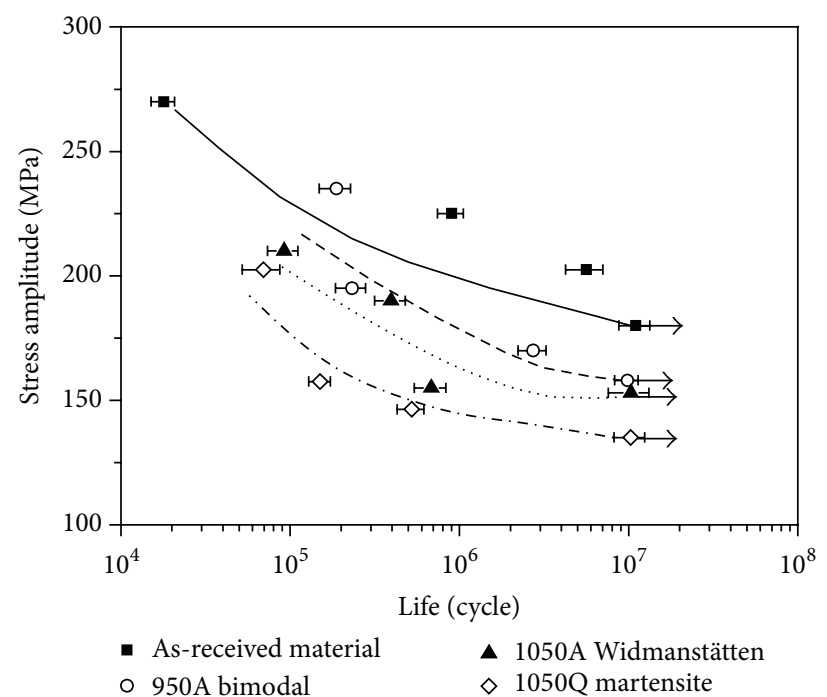

FIGURE 9: Stress amplitude versus life curves of AR material, martensite, Widmanstätten, and bimodal microstructures of Ti6Al4V.

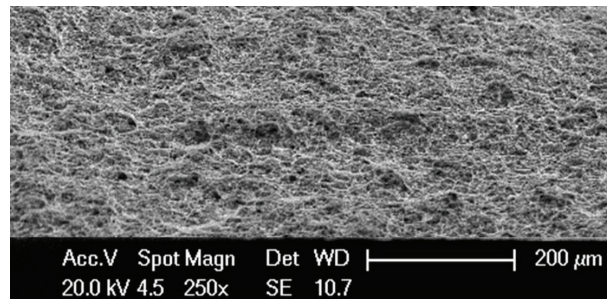

(a)

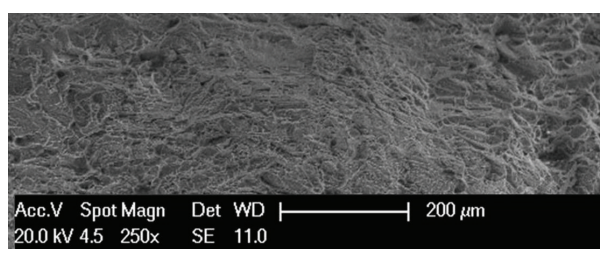

(c)

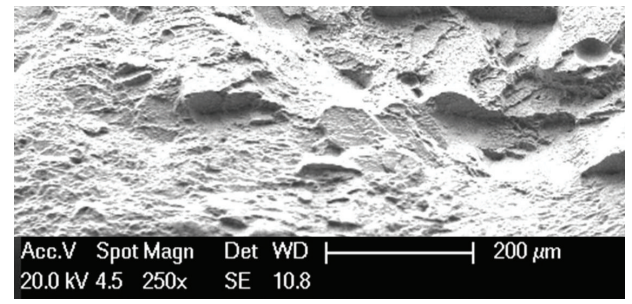

(b)

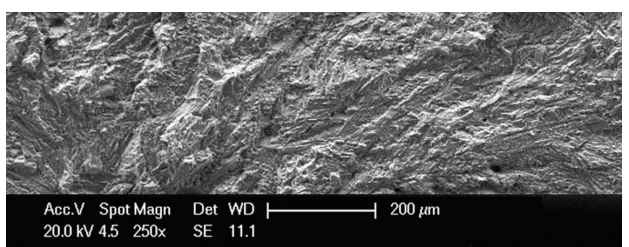

(d)

FIGURE 10: SEM fractographs of the high-cycle fatigue samples of (a) AR material, (b) 1050Q, (c) 950A, and (d) 1050A.

and globularization. Temperatures of $650^{\circ} \mathrm{C}-850^{\circ} \mathrm{C}$ are normally used for these. As shown in Figures 3(b)-3(f), the microstructures were not modified. There is no significant difference in the mechanical properties (hardness, $0.2 \%$ proof stress, and elongation) associated with heat treatment at these temperatures. In industrial application, stress relief, recrystallization, and globularization can be realized by annealing at $650^{\circ} \mathrm{C}-850^{\circ} \mathrm{C}$; however, the associated oxidation layer thickness increases at the same time [24].

Water quenching from $850^{\circ} \mathrm{C}$ to $1050^{\circ} \mathrm{C}$ tends to increase the strength owing to higher $\beta$ phase content [10]. Water quenching at $1050^{\circ} \mathrm{C}$ (Figure $3(\mathrm{k})$ ) transformed the equiaxed microstructure into acicular $\alpha^{\prime}$ martensite microstructure. The martensite sample exhibited the highest increases in hardness $(419 \mathrm{HV})$ and $0.2 \%$ proof stress (13.8\%) compared to the AR sample but at the cost of a reduction in ductility (42.7\% lower elongation compared to the AR sample). Similar results for mechanical properties of acicular $\alpha^{\prime}$ martensite microstructure of Ti6Al4V were obtained by Jovanović et al. [10]. By comparing the results of this paper with Jovanovic et al.'s data ( $0.2 \%$ proof stress: $1400 \mathrm{MPa}$; elongation: $1.5 \%$, water quenching from $1100^{\circ} \mathrm{C}$ ), it is obvious that the values of $0.2 \%$ proof stress (1114 MPa) of acicular $\alpha^{\prime}$ martensite microstructure in this study are lower, but elongation (7.8\%) is rather higher. Jovanović et al. suggested two reasons for these differences: (1) Their AR materials were Widmanstätten with a massive $\beta$ phase boundary that exhibited higher strength $(1100 \mathrm{MPa})$ but lower ductility $(<1.5 \%)$ and $(2)$ the presence of $\mathrm{TiC}$ (formed from carbon diffused into the melt, forming carbides with titanium and vanadium during the casting process) raised the tensile strength but compromised ductility. The fatigue strength of the acicular $\alpha^{\prime}$ martensite microstructure is the lowest $(135 \mathrm{MPa})$, being lower than the AR material by $45 \mathrm{MPa}$. The term "fatigue" relates to 
TABLE 2: Summary of the study showing absolute values and variance $(\Delta \%)$ of properties of AR materials.

\begin{tabular}{|c|c|c|c|c|c|c|}
\hline \multirow{2}{*}{ Microstructure } & \multicolumn{2}{|c|}{$0.2 \%$ proof stress } & \multicolumn{2}{|c|}{ Elongation } & \multicolumn{2}{|c|}{ Fatigue strength } \\
\hline & $(\mathrm{MPa})$ & $(\Delta \%)$ & $(\%)$ & $(\Delta \%)$ & $(\mathrm{MPa})$ & $(\Delta \%)$ \\
\hline $\begin{array}{l}\text { As-received } \\
\text { (equiaxed grain size }=15-20 \mu \mathrm{m})\end{array}$ & 978 & 0 & 13.6 & 0 & 180 & 0 \\
\hline $\begin{array}{l}\text { Bimodal }(950 \mathrm{~A}) \\
\text { (equiaxed grain size }=15-20 \mu \mathrm{m}+ \\
\text { lamellar width of } 2-4 \mu \mathrm{m})\end{array}$ & 1017 & 4.00 & 11.8 & -13.6 & 158 & -12.2 \\
\hline $\begin{array}{l}\text { Widmanstätten }(1050 \mathrm{~A}) \\
\text { (lamellar width of } 10 \mu \mathrm{m}+ \\
>400 \mu \mathrm{m} \alpha \text { grain boundary) }\end{array}$ & 1041 & 6.42 & 10.3 & -24.4 & 153 & -15 \\
\hline $\begin{array}{l}\text { Martensite (1050Q) } \\
(200 \mu \mathrm{m} \text { grain size with inside } \\
\left.\text { acicular } \alpha^{\prime}\right)\end{array}$ & 1114 & 13.8 & 7.8 & -42.7 & 135 & -25 \\
\hline
\end{tabular}

the initiation and growth of cracks caused by the repeated application of mechanical stresses or strains and any associated changes in mechanical properties [21]. Sun et al. [25] reported that low ductility deteriorated fatigue propagation resistance in tensile mode fracture, but high strength did little to help fatigue initiation resistance $[25,26]$. Hence, the poor ductility in the acicular $\alpha^{\prime}$ martensite microstructure is one reason why its fatigue strength is so low. The coarsegrained structure (Figure $3(\mathrm{k})$ ) can be another reason for brittle fatigue fracture (Figure 10(b)). It is well known that fatigue cracking in Ti6Al4V alloys starts at prior $\beta$ grain boundaries or colony boundaries and $\alpha / \beta$ interfaces [27]. A coarse-grained structure will aggravate dislocations at the prior $\beta$ grain boundaries [28] and eventually lead to failure. A third reason for the lower fracture strength in martensite could be martensite transformation stress; generally, it is easier to initiate cracks at a stress-concentration position [29]. Martensite transformation stress may aggravate the stress concentration.

Ti6Al4V heat-treated at $950^{\circ} \mathrm{C}$ followed by annealing (Figure 3(h)) exhibits slight lamellar microstructure at prior $\beta$ phase boundaries. Such bimodal microstructure (consisting partly of equiaxed primary $\alpha$ and a lamellar $\alpha+$ $\beta$ matrix transformed from a prior $\beta$ phase boundary) results from heat treatment just below the $\beta$ transus temperature $[13,30]$. Tensile test results show (Figure 7 ) that bimodal microstructures exhibit well-balanced properties between $0.2 \%$ proof strength (1017 $\mathrm{MPa})$ and ductility $(11.8 \%)$. The Widmanstätten microstructure heat-treated at $1050^{\circ} \mathrm{C}$ followed by annealing exhibits a slightly higher strength $(1041 \mathrm{MPa})$ than the bimodal microstructure but has lower ductility $(10.3 \%)$ than the bimodal microstructure. This research indicated that $\mathrm{Ti} 6 \mathrm{Al} 4 \mathrm{~V}$ with bimodal microstructure has a slightly higher fatigue strength than that with Widmanstätten microstructure. Similar results were obtained by Zuo et al. [30]. The fatigue strengths for their bimodal and Widmanstätten microstructures were 493 and $475 \mathrm{MPa}$, respectively (with both the stress ratio $R=-1$ and frequency $=20 \mathrm{kHz}$ increasing the fatigue strength). Both Zuo et al. [30] and Gil et al. [5] have concluded that crack initiation rather than crack propagation plays the dominant role in controlling the total life in high-cycle fatigue when there are not too many interior defects. Equiaxed microstructure benefits fatigue initiation resistance. Hence, bimodal microstructure (with the properties of primary $\alpha$ grain of slightly lower strength and higher ductility) exhibits higher fatigue life compared with Widmanstätten microstructure (which is a special type of lamellar microstructure). However, bimodal microstructure exhibits lower fatigue life compared with equiaxed microstructure owing to its lower ductility compared with AR microstructure. The fine dimple patterns observed in fractographs of AR samples may indicate a plastic fatigue fracture process. The AR material has an equiaxed microstructure that exhibited the highest ductility (13.6\%).

The correlations among the microstructures, mechanical properties, and fatigue strengths of $0.7 \mathrm{~mm}$ Ti6Al4V sheet are listed together in Table 2.

\section{Conclusions}

This study highlights the role of microstructure on fatigue strength rather than relying on the broader relationship between ductility and fatigue strength. Three key observations are apparent:

(1) The $0.2 \%$ proof stress ranking from high to low for all types of microstructure of thin Ti6Al4V sheets observed in this study is as follows: acicular $\alpha^{\prime}$ martensite, equiaxed microstructure with metastable $\beta$, Widmanstätten, bimodal, and equiaxed microstructure.

(2) The ductility ranking from high to low for all types of the microstructure of thin Ti6Al4V sheets observed in this study is as follows: equiaxed, bimodal, Widmanstätten, and martensite microstructure.

(3) The fatigue strength ranking from high to low for the microstructure of thin Ti6Al4V sheets observed in this study is as follows: equiaxed, bimodal, Widmanstätten, and acicular $\alpha^{\prime}$ martensite microstructure.

The fatigue strength of thin Ti6Al4V sheets decreases inversely proportionally with the proof stress and proportionally with ductility; this is in response to the types of 
microstructure and grain sizes set up in the heat-treatment processes.

\section{Conflict of Interests}

The authors declare that there is no conflict of interests regarding the publication of this paper.

\section{Acknowledgments}

The authors wish to acknowledge the materials support provided by Timet UK Limited. The work is supported by Fundamental Research Funds for the Central Universities (2014QNA09), Natural Science Foundation of Jiangsu (BK20150205), and Postdoctoral Science Foundation of Jiangsu (1501029A). The authors also wish to express heartfelt thanks to Professor Philip Shipway and Professor Geoff Tansley for encouragement, supervision, and support throughout the work.

\section{References}

[1] G. D. Tansley, M. Cook, N. Zhang, M. Chung, J. Woodard, and J. Reizes, Complete Passive Suspension of the Ventrassist Rotary Blood Pump, Univerisy of Technology, Sydney, Australia, 2000.

[2] G. Tansley, S. Vidakovic, and J. Reizes, "Fluid dynamic characteristics of the VentrAssist rotary blood pump," Artificial Organs, vol. 24, no. 6, pp. 483-487, 2000.

[3] Y. Fan, Z. Chen, C. H. Zhang, and A. M. Liu, "A comparison of microstructure and mechanical properties of welded thin Ti6Al4V with three different types of laser," Materials Research Innovations, vol. 19, no. S4, pp. S187-S192, 2015.

[4] L. W. Tsay and C. Y. Tsay, "Effect of microstructures on the fatigue crack growth in Ti6Al4V laser welds," International Journal of Fatigue, vol. 19, no. 10, pp. 713-720, 1997.

[5] F. J. Gil, M. P. Ginebra, J. M. Manero, and J. A. Planell, "Formation of $\alpha$-Widmanstätten structure: effects of grain size and cooling rate on the Widmanstätten morphologies and on the mechanical properties in Ti6Al4V alloy," Journal of Alloys and Compounds, vol. 329, no. 1-2, pp. 142-152, 2001.

[6] F. Caiazzo, F. Curcio, G. Daurelio, and F. M. C. Minutolo, "Ti6Al4V sheets lap and butt joints carried out by $\mathrm{CO}_{2}$ laser: mechanical and morphological characterization," Journal of Materials Processing Technology, vol. 149, no. 1-3, pp. 546-552, 2004.

[7] I. J. Polmear, Light Alloys: From Traditional Alloys to Nanocrystals, Butterworth-Heinemann, Oxford, UK, 2006.

[8] N. Poondla, T. S. Srivatsan, A. Patnaik, and M. Petraroli, "A study of the microstructure and hardness of two titanium alloys: commercially pure and Ti-6Al-4V,' Journal of Alloys and Compounds, vol. 486, no. 1-2, pp. 162-167, 2009.

[9] M. Žitňanský and L. Čaplovičc, "Effect of the thermomechanical treatment on the structure of titanium alloy Ti6Al4V," Journal of Materials Processing Technology, vol. 157-158, pp. 643-649, 2004.

[10] M. T. Jovanović, S. Tadić, S. Zec, Z. Mišković, and I. Bobić, "The effect of annealing temperatures and cooling rates on microstructure and mechanical properties of investment cast Ti-6Al-4V alloy," Materials and Design, vol. 27, no. 3, pp. 192199, 2006.
[11] D. Hardie and S. Ouyang, "Effect of microstructure and heat treatment on fracture behaviour of smooth and precracked tensile specimens of Ti6Al4V," Materials Science and Technology, vol. 15, no. 9, pp. 1049-1057, 1999.

[12] S. Shademan, V. Sinha, A. B. O. Soboyejo, and W. O. Soboyejo, "An investigation of the effects of microstructure and stress ratio on fatigue crack growth in Ti-6Al-4V with colony $\alpha / \beta$ microstructures," Mechanics of Materials, vol. 36, no. 1-2, pp. 161-175, 2004.

[13] C. Leyens and M. Peter, Titanium and Titanium Alloys: Fundamentals and Applications, Wiley-VCH Verlag $\mathrm{GmbH} \& \mathrm{Co}$. KGaA, 2003.

[14] C. Loier, G. Thauvin, A. Hazotte, and A. Simon, "Influence of deformation on the $\beta \rightarrow \alpha+\beta$ transformation kinetics of Ti6 wt.\%Al-4 wt.\%V alloy," Journal of the Less Common Metals, vol. 108, no. 2, pp. 295-312, 1985.

[15] T. Mohandas, D. Banerjee, and V. V. K. Rao, "Fusion zone microstructure and porosity in electron beam welds of an $\alpha+\beta$ titanium alloy," Metallurgical \& Materials Transactions A, vol. 30, no. 3, pp. 789-798, 1999.

[16] T. Ahmed and H. J. Rack, "Phase transformations during cooling in $\alpha+\beta$ titanium alloys," Materials Science and Engineering, vol. 243, no. 1-2, pp. 206-211, 1998.

[17] American Welding Society, Recommended Practices for Laser Beam Welding, Cutting and Drilling, AWS/ANSI, 1998.

[18] X. Li, Research on the Microstructure and Fatigue Property of Electron Beam Welding Joint in Titanium Alloy, Huazhong University of Science and Technology, Wuhan, China, 2012.

[19] C. Wu, X. Li, X. Huang, J. Ma, and C. Cao, "Relationship of fatigue crack propagation and microstructure for TA15 alloy," Rare Metal Materials and Engineering, vol. 36, no. 12, pp. 21282131, 2007.

[20] European Standard EN10002-1, Metal material: Tensile test, 2001.

[21] British Standard 3518-1: Methods of fatigue testing, 1993.

[22] W. Sha and Z. Guo, "Phase evolution of Ti-6A1-4V during continuous heating," Journal of Alloys and Compounds, vol. 290, no. 1-2, pp. L3-L7, 1999.

[23] P. Sirilar and P. Srichandr, Grain Refinement of $\alpha / \beta$ Phase Ti6Al4V Alloy by Thermomechanical Treatment, King Mongkut's University of Technology Thonburi, Bangkok, Thailand, 2006.

[24] Y. Fan, G. D. Tansley, P. H. Shipway, and J. Niu, “The application of laser welding on Left Ventricular Assist Device (LVAD)," in Proceedings of the Symposium on Photonics and Optoelectronics (SOPO '11), pp. 1-3, Wuhan, China, May 2011.

[25] Z. Sun, L. Jiang, and Z. Ying, Failure Analysis: Fundamentals and Applications, China Machine Press, 2005.

[26] X. L. Zheng, Quantitative Theory of Metal Fatigue, Northwestern Polytechnical University Press, 1994.

[27] J. Oh, N. J. Kim, S. Lee, and E. W. Lee, "Correlation of fatigue properties and microstructure in investment cast Ti-6Al-4V welds," Materials Science and Engineering A, vol. 340, no. 1-2, pp. 232-242, 2003.

[28] F. X. Gil Mur, D. Rodríguez, and J. A. Planell, "Influence of tempering temperature and time on the $\alpha^{\prime}$-Ti-6Al-4V martensite," Journal of Alloys and Compounds, vol. 234, no. 2, pp. 287-289, 1996. 
[29] S. R. Lampman and N. Dimatteo, Fatigue and Fracture, ASM International, Geauga County, Ohio, USA, 1996.

[30] J. H. Zuo, Z. G. Wang, and E. H. Han, "Effect of microstructure on ultra-high cycle fatigue behavior of Ti-6Al-4V," Materials Science and Engineering: A, vol. 473, no. 1-2, pp. 147-152, 2008. 

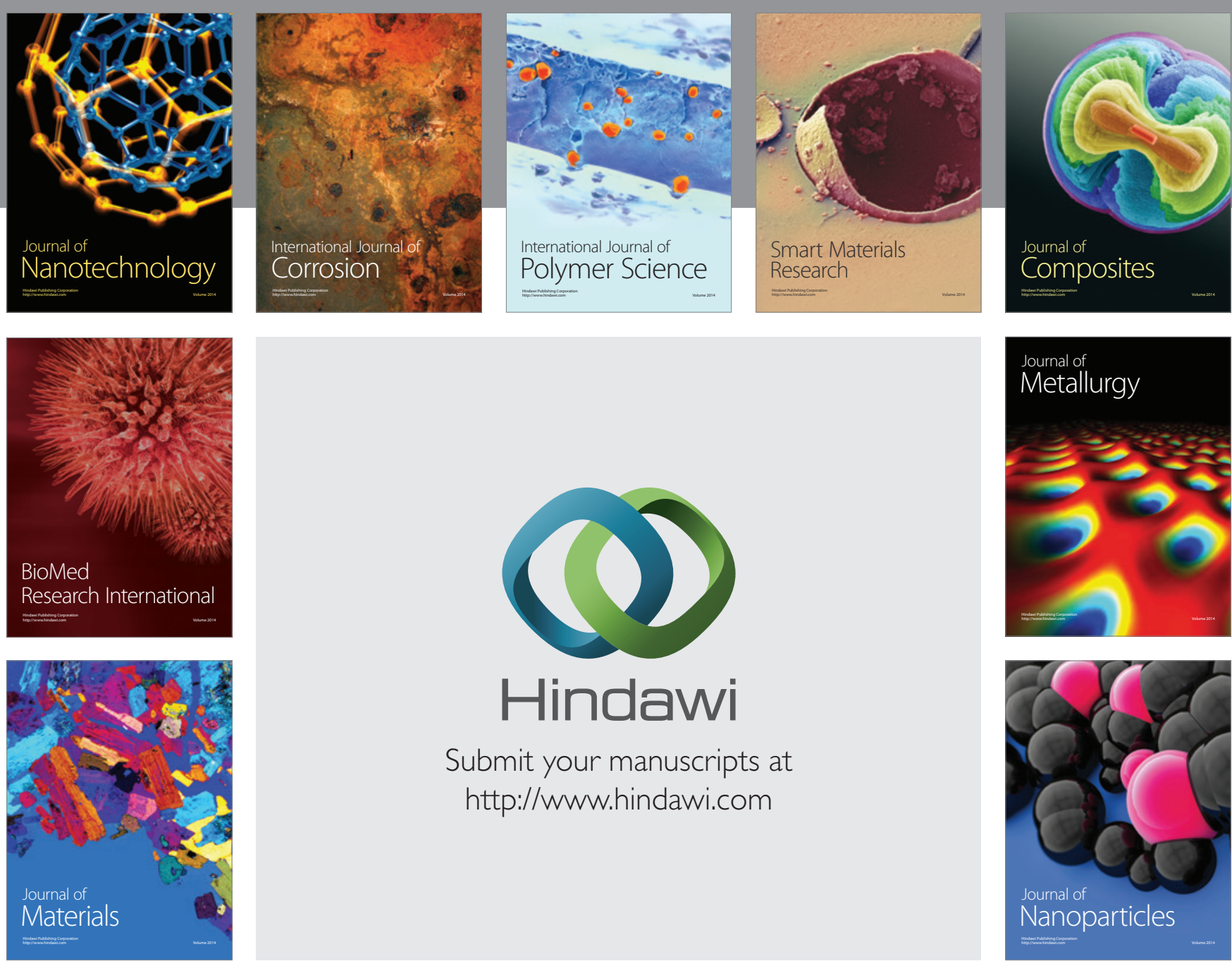

\section{Hindawi}

Submit your manuscripts at

http://www.hindawi.com

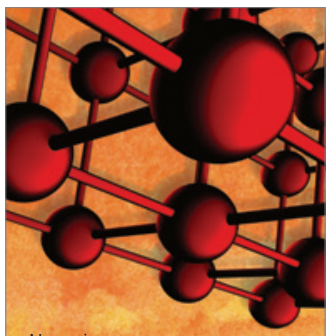

Materials Science and Engineering
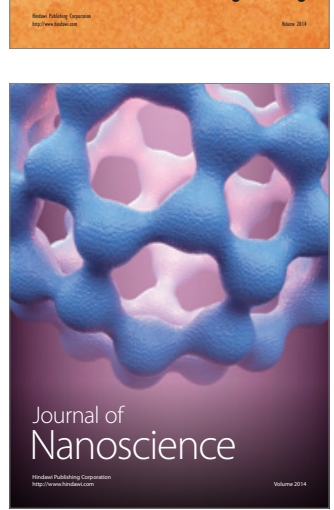
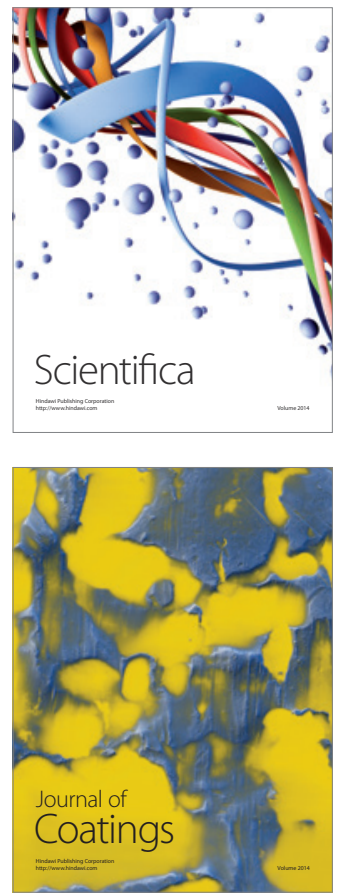
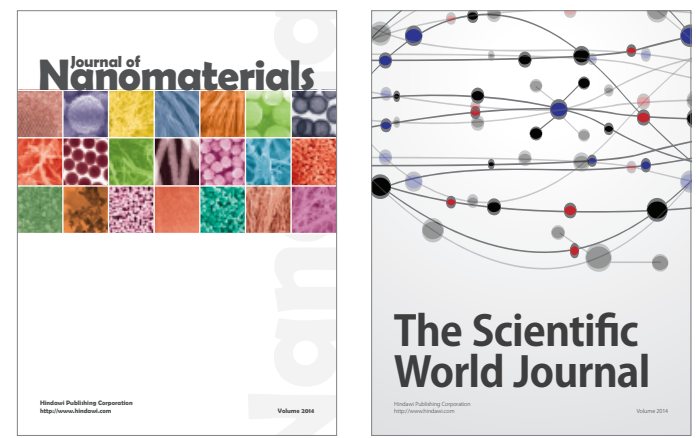

The Scientific World Journal
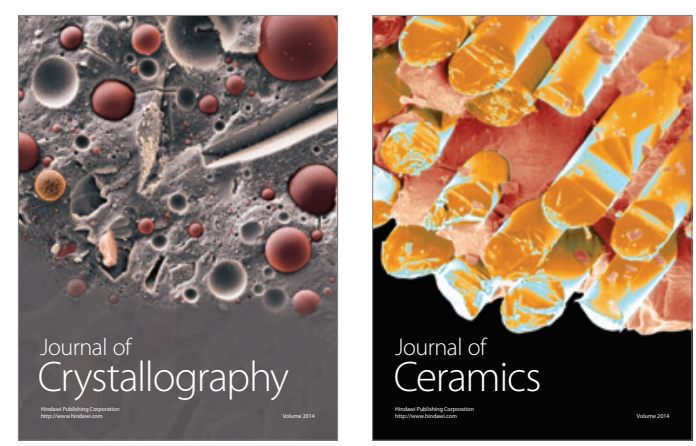
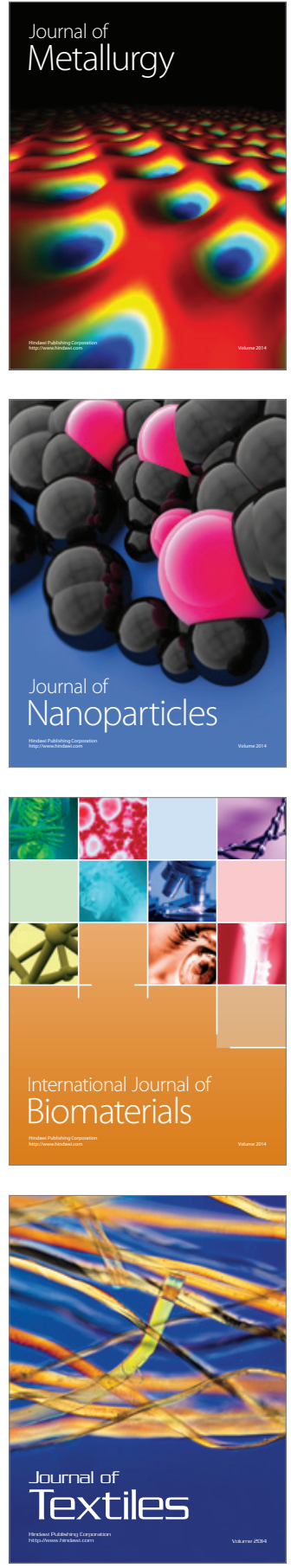